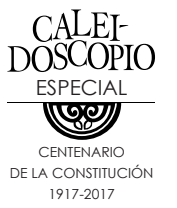

\title{
Presentación de Ramírez (2017). El sublime arte de Apeles. Historia de la enseñanza del dibujo en Aguascalientes (1832-1925)
}

\author{
Presentation of Ramírez (2017). \\ El sublime arte de Apeles. Historia de la enseñanza \\ del dibujo en Aguascalientes (1832-1925)
}

GABRIELA ITZAGUERI MENDOZA SÁNCHEZ1

Ramírez Hurtado, L. (2017). El sublime arte de Apeles. Historia de la enseñanza del dibujo en Aguascalientes (1832-1925). Aguascalientes: Universidad Autónoma de Aguascalientes.

Es un honor para mí estar en esta mesa ${ }^{2}$ con los historiadores Luciano Ramírez, Caliope Martínez, Enrique Rodríguez Varela y la audiencia. Muchas gracias al doctor Luciano por la invitación y por haber realizado el libro que hoy presentamos acerca de la enseñanza del dibujo. Mis felicitaciones a la Universidad, en particular al Departamento Editorial, encabezado por la

gabrielaitzagueri@yahoo.com.mx.

2 Este texto tuvo lugar en el evento de presentación del libro el 13 de abril de 2018 en las instalaciones de la Universidad Autónoma de Aguascalientes. maestra Martha Esparza, por el cuidado en la realización del libro.

El sublime arte de Apeles. Historia de la enseñanza del dibujo en Aguascalientes (1832-1925) es el resultado de una ardua y minuciosa investigación que revisa tanto los acontecimientos en la Academia de dibujo de Aguascalientes, como lo sucedido en espacios próximos o relacionados con dicha Academia a lo largo de un siglo. Es un recorrido cuidadoso a través de un periodo amplio en el tiempo y, a la vez, es una lectura que se disfruta porque recupera varias de las ideas que se han tenido del dibujo y reconstruye el 
acontecer, de manera que podemos ir visualizando las diferentes etapas de esta historia a través de la integración de un amplio número de fuentes diversas.

Concuerdo completamente con el doctor Luciano en que, como nos señala en el libro, existía un hueco con respecto a lo que sabíamos acerca del desarrollo de la enseñanza de las artes, particularmente del dibujo, en nuestro país. Además, podríamos pensar en lo indispensable que resulta el aporte del arte, de nuestras construcciones simbólicas, para la comprensión de las sociedades. Entonces, este libro es, además de vigente, necesario.

La organización de los capítulos y apartados resalta los sucesos que fueron relevantes, sobre todo para la vida de la Academia de dibujo. La lectura del libro nos lleva a través del eje que constituye el estudio de la Academia de Dibujo en Aguascalientes a tener un acercamiento al panorama nacional, incluso al internacional y a las discusiones en los distintos momentos acerca de la enseñanza de las artes. Desde las primeras páginas, podemos encontrar citas que recuperan las ideas que tenían diferentes personajes, acerca del dibujo y su impartición; palabras y argumentaciones a favor del dibujo que, en tiempos más recientes, parecen haberse olvidado. Un ejemplo de las ideas que forman parte de este libro está en Amador Herrera, quien apuntó:

El dibujo facilita el estudio de la ciencia, perfecciona las artes y economiza el triunfo, cría amor al trabajo, envolviéndolo y haciéndolo producir la riqueza contenida en los brazos del hombre; al humilde artesano y más al mexicano, si se le exige que lo estudie, saldrá de la esfera, dejará de ser un servil admirador e imitador de las obras extranjeras; no será un autómata que maquinalmente ejecute lo que otro y otros mil han hecho con más o menos perfección, porque una vez sabiendo dibujar, sabrá inventar y embellecer sus artefactos; la experiencia nos demostró que el que se ha dedicado al dibujo en su infancia, aun cuando no haya llegado a la perfección, es más preciso y expedito en la profesión que tiene; sus obras son más perfectas y acabadas y siempre puede, sin perjuicio, nivelarse a las circunstancias de la época en que vive [...] (Ramírez, 2017: 212).

Podremos confirmar con el autor, al seguir la reconstrucción de los momentos en que se expresaban ideas como las anteriores, que existía un gran interés por la enseñanza del dibujo. 
Dentro de los cambios importantes a favor de la educación en general y de los cambios sociales más trascendentes, podemos reconocer el hecho de la oportunidad que se diera a las niñas para asistir a la escuela. Al respecto, el investigador nos comparte una de las declaraciones sobre el Liceo de Niñas:

No fue el espíritu de rutina ni de servil imitación lo que impulsara a los Sres. [Alfredo] Lewis y [José] Bolado al iniciar esta idea, sino el profundo convencimiento que abrigaban, la íntima persuasión que tenían, del papel elevado que desempeña la mujer en la familia, u por lo mismo en la sociedad. En efecto, señor, instruir al hombre es formar un solo miembro de la gran familia humana, mientras que instruir a la mujer, es educar a una familia entera, puesto que ella es por naturaleza la institutriz de la infancia en el hogar doméstico (Ramírez, 2017: 1).

El libro nos mantiene interesados, nos permite hacernos una idea completa de cómo se pensaba el dibujo y cómo se enseñaba, de aspectos de la educación en los momentos de transformaciones, tensiones y reconstrucciones. Además, el autor nos ayuda a ir siguiendo la pista a los personajes de quienes nos podríamos cuestionar su relevancia. La investigación atiende la formación, incursión y participación de varios artistas, como Posada, Herrán, Francisco Díaz de León, Jesús F. Contreras, Guillermo Ruiz, el Dr. Atl; y así también, representa una lectura invaluable para quienes están investigando a los Chávez como ustedes saben, con respecto a su establecimiento llamado "El Esfuerzo".

En lo personal, el interés en Saturnino Herrán ha estado centrado en su aportación al arte, pero me resultó entrañable y coherente con la idea del artista que podemos imaginar con la siguiente descripción: "Saturnino Herrán, 'el chico irónico, socarón y espiritual del Instituto de Aguascalientes', expresión de algún escritor incluida por Sebastián Preciado Rodríguez en Un viaje al pasado con el Dr. Pedro de Alba" (Ramírez, 2017: 268), y que podemos leer en este libro.

A la par de las líneas que nos permiten dibujar ideas más completas acerca de nuestros artistas, se incluyen referencias necesarias para analizar de manera crítica el desarrollo de las artes en nuestro país. Luciano Ramírez nos lleva a ahondar en la siguiente cita, opinión expresada en 1958 por Francisco Díaz de León, acerca de las academias: 
Confieso sinceramente que aprendí poco en aquel templo del arte, y también, que las litografías de Julien, aquellas muestras ante las cuales permanecían hipnotizados meses y meses los alumnos, sólo despertaron en mí temor y desconcierto. No dibujaría ya con mi antigua libertad. Al trazo libre, espontáneo, con que solía evocar el mundo físico, le sucedía un fastidioso grafismo de líneas con gruesos y delgados que eran modulados con minucia aterradora. Fui el más mediocre entre todos los vespertinos concurrentes y desde aquellos lejanos días enemigo de las academias (Ramírez, 2017: 275; Ruiz, 1998: 9 y 40).

Esta cita es acompañada con una nota amplia a pie de página, que nos lleva a comprender que los artistas tenían una constante preocupación por las metodologías aplicadas para la enseñanza de las artes, ya que, a pesar de la afirmación de Díaz de León, de "que era enemigo de las academias", queda de manifiesto su deseo de colaborar en dicha enseñanza.

Como podemos advertir gracias a la minuciosa reconstrucción histórica, es posible conocer las dificultades administrativas, los principales protagonistas, las metodologías de enseñanza. Si para el lector que se dedica al dibujo resultan deliciosos estos detalles, para los que no se dedican al dibujo resultarán atractivos para acercarse a tan ancestral expresión.

Es una historia que estábamos necesitando y que el doctor Luciano convoca a continuar. Como una invitación a reflexionar sobre nuestro presente -porque me parece que no ha perdido actualidad-, encontramos la afirmación de Manuel Gómez Portugal al lamentar el despido del pintor José Inés Tovilla:

En el medio en que vivimos, el artista es aún algo raro y extraño que no se alcanza a comprender: un ser que va fuera del camino trillado que la vulgaridad recorre con sus zapatones de suelas ferradas, y su paraguas blanco para precaverse del sol; un soñador que marcha viendo hacia las estrellas para sorprender los tesoros de su belleza, y se olvida de los otros tesoros más reales que dan la usura, el lucro, el negocio más o menos honrado del tanto por ciento $[\ldots]$.

Así vamos caminando! [...] Entre tanto en estas líneas le mando al amigo y al artista una despedida sincera y cariñosa (Ramírez, 2017: 283).

Con estas palabras y la constelación de acontecimientos que 
ha reconstruido, con la reunión de las diferentes ideas e intereses que estuvieron en torno a la enseñanza de las artes, Luciano Ramírez colabora de manera trascendente con el conocimiento y la comprensión de las artes desde distintas regiones, para, por supuesto, pensar nuestro presente. En su epílogo nos dice: "Constatamos que la enseñanza del dibujo fue considerada la base de las demás artes plásticas, oficios artesanales y ciencias en general, así como para cualquier actividad de la vida diaria, esto es, como la palanca de la civilización" (Ramírez, 2017: 331). Por este arduo trabajo y por estas líneas, mi agradecimiento, porque estoy convencida de que dibujar es una forma de ensayar el pensa- miento; convencida, en fin, de lo significativo que es dibujar.

Sin más, únicamente me resta afirmar que es una lectura altamente recomendable para los interesados en la historia e indispensable para los estudiosos de la educación y del arte. Gracias por la atención. Gracias, Luciano, y felicitaciones también por las investigaciones actualmente emprendidas que se relacionan, en cierto modo, con el presente libro.

\section{REFERENCIAS}

Ruiz Naufal, V. M. (1998). Francisco Díaz de León. Creador y maestro. Aguascalientes: Instituto Cultural de Aguascalientes 